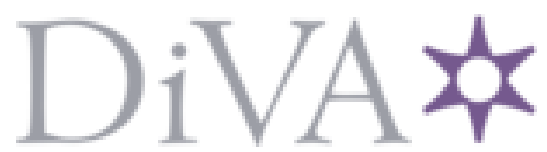

http://www.diva-portal.org

This is the published version of a paper presented at 1oth Nordic Conference on HumanComputer Interaction (NORDICHI) 2018.

Citation for the original published paper:

Björnfot, P., Farshidi, A., Kaptelinin, V. (2018)

Employing the secondary task technique for measuring MRP pilots' cognitive load In: Proceedings of the 1oth Nordic Conference on Human-Computer Interaction (pp. 706-710). ACM Press

https://doi.org/10.1145/3240167.3240249

N.B. When citing this work, cite the original published paper.

Permission to make digital or hard copies of part or all of this work for personal or classroom use is granted without fee provided that copies are not made or distributed for profit or commercial advantage and that copies bear this notice and the full citation on the first page. Copyrights for third-party components of this work must be honored. For all other uses, contact the Owner/Author.

Permanent link to this version:

http://urn.kb.se/resolve?urn=urn:nbn:se:umu:diva-152827 


\section{Employing the Secondary Task Technique for Measuring MRP Pilots' Cognitive Load}

Patrik Björnfot

Umeå University

901 87, Umeå, Sweden

patrik.bjornfot@umu.se

\section{Azadeh Farshidi}

Umeå University

901 87, Umeå, Sweden

azadeh.farshidi@gmail.com

\section{Victor Kaptelinin}

Umeå University

901 87, Umeå, Sweden

victor.kaptelinin@umu.se

Permission to make digital or hard copies of part or all of this work for personal or classroom use is granted without fee provided that copies are not made or distributed for profit or commercial advantage and that copies bear this notice and the full citation on the first page. Copyrights for third-party components of this work must be honored. For all other uses, contact the Owner/Author.

NordiCHI'18, September 29-October 3, 2018, Oslo, Norway

(c) 2018 Copyright is held by the owner/author(s).

ACM ISBN 978-1-4503-6437-9/18/09.

https://doi.org/10.1145/3240167.3240249

\begin{abstract}
Mobile Remote Presence (MRP) technologies make it possible for the user to be mobile in a remote environment, which opens up new possibilities for interaction. However, this new functionality comes at a cost. The need for MRP system users to pay attention to both telecommunication and device navigation increases their cognitive load. Assessing the cognitive load of MRP system users is a timely research issue, which is addressed in this paper both conceptually and empirically. We argue that Secondary Task (ST) techniques have certain advantages over existing Subjective Rating Scales (SRS) instruments, and report a study, in which a particular ST technique, a visual monitoring task, was employed to assess MRP pilot's cognitive load. The empirical evidence from the study indicates that the method provides additional valuable insights into MRP pilots' user experience.
\end{abstract}

\section{Author Keywords}

Cognitive load; Cognitive load measurement; Secondary task; Mobile Remote Presence (MRP); Subjective rating scales (SRS) 


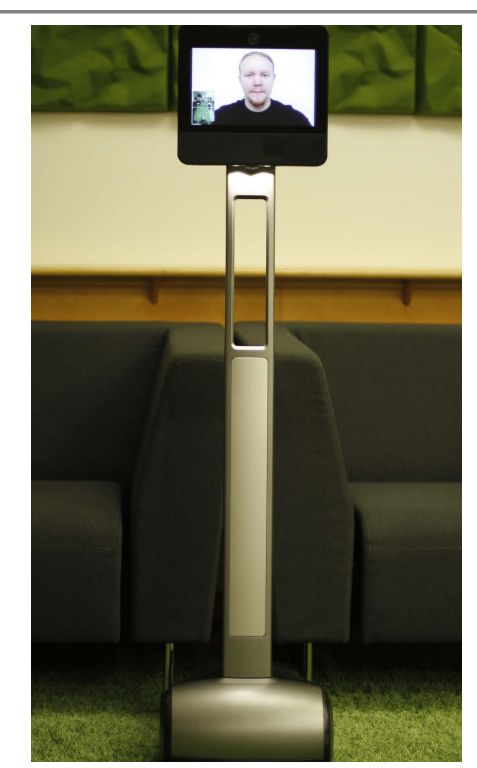

Figure 1: BEAM+ from

SuitableTech

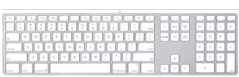

Keyboard
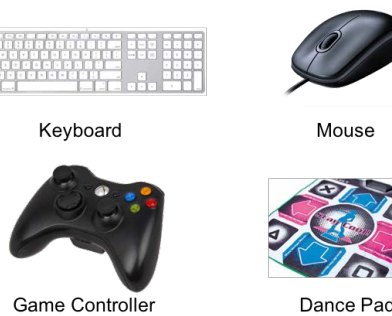

Mouse

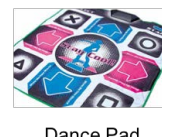

Dance Pad

Figure 2: The Four Input Devices

\section{ACM Classification Keywords}

H.5.2. Information interfaces and presentation: User Interfaces; Theory and methods.

\section{Introduction}

Mobile Remote Presence (MRP) robots (see Figure 1) are remotely controlled devices that combine videoconference functionality with physical navigation capabilities. Studies indicate that MRP systems have advantages over stationary video-conference systems. MRP systems users ("pilots") can approach individual people at the time and place of pilots' own choosing, and therefore have more opportunities for initiating remote interaction $[10,11,15]$. Thus, MRP systems make it possible for the pilots to significantly increase their level of physical and social presence in a remote environment.

A key challenge for the design of MRP systems is dealing with pilots' cognitive load. Since controlling an MRP system is a cognitively challenging task, it is important to make sure users' focus is on meaningful goals of their activities rather than on operating the system [9]. However, to the best of our knowledge, little attention has been paid to the cognitive load of MRP pilots. In general, the cognitive load of users of remotely controlled devices is a research issue that has been mostly explored in the context of military applications [5, 12] and medicine [2].

The purpose of the study reported in this paper was to develop and evaluate a Secondary Task (ST) method for measuring the cognitive load of MRP pilots. The STmethod was developed and evaluated as a part of a larger study, in which a comparative analysis of four different types of input devices (see Figure 2) for controlling the BEAM+ MRP system (see Figure 1 ) was performed. The participants in the study were required to drive the MRP system through a track that presented a number of challenges (see Figure 3). Data collected from a variety of sources were analyzed to make conclusions about the validity and usefulness of the STmethod.

Secondary Task for measuring cognitive load Cognitive load is defined as the effort that performing a task puts on a person's cognitive system [13], and is commonly measured by analytical and/or empirical methods $[12,16]$. Analytical methods estimate the mental load by using expert opinions and analytical data. Empirical methods include collecting subjective data (for example, with Subjective Rating Scales, SRS), Performance-based techniques (such as Secondary Task, ST), and psychophysiological techniques.

Secondary Task is a simple, measurable, activity, which requires a specific level of attention, and which the participant performs in parallel with the Primary Task. Performance measurements (e.g. reaction time, accuracy and error rate), of the Secondary Task work as an indication of the cognitive load of the Primary Task. The main benefit of the Secondary Task

technique compared to Subjective Rating Scales is objectivity and that the measurement is performed in real time [1]. In recent years Secondary Task methods have been used in various studies as the sole method $[3,6]$ or in combination with Subjective Rating Scales $[3,7,14]$. A common implementation of the Secondary Task technique is to use visual monitoring, such as in [2]. Visual monitoring ensures the continuity of assessment, which, given the right level of intensity 


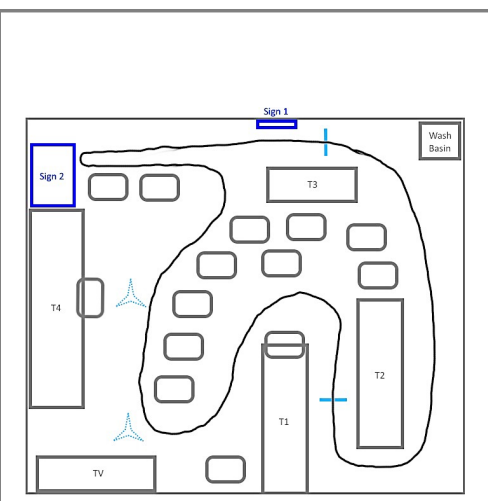

Figure 3: Track consisting of: two start/ stop positions (blue lines), two signs (blue rectangles), and two hanging objects (triangles).

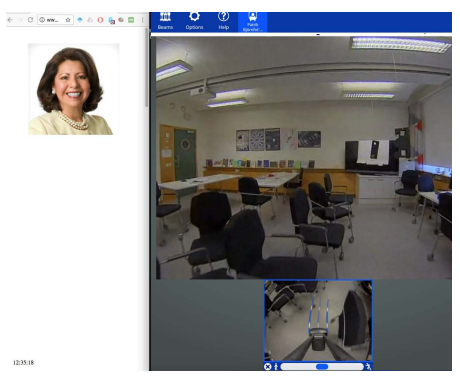

Figure 4: Screenshot of the UI, ST (left) and MRP control (right). and frequency of visual stimuli, decreases the probability of missing cognitive load peak moments.

\section{Method}

Participants. Sixteen participants, 23-49 y.o., nine males and seven females, took part in the study. The study employed a convenience sampling snowballing technique. None of the participants had any previous experience with MRP.

The secondary task technique. The secondary task stimuli consisted of 85 portraits displayed, randomly, for 5 seconds consecutively, to the pilot. The pilot was familiarized with two portraits, one male and one female, before each session, and was required to respond the portraits by greeting them. The portrait size mimicked the size of a proximate persons face viewed through the MRP UI (see Figure 4). The portraits were selected based on similarities in color, size, and style, so that the participants could not assess the portraits by only using peripheral vision.

The choice of the secondary task was partly based on the relevance of the task to expected use-scenarios for $M R P$, in line with $[2,7]$. Furthermore, the visual monitoring task can be argued to provide the appropriate kind of distraction, since it demands the same type mental resources [13] as the main navigation task; in both tasks, pilots had to receive and handle visual cues. The ST was presented side-by-side with the MRP UI (see Figure 4). Both screen images and audio were recorded for assessing ST performance.

Procedure. Each session comprised four phases: 1) introduction, 2) background information questionnaire, 3) four driving episodes, and 4) a concluding interview. The pilot was located in a university office and the BEAM+ was located in another room of the same building.

The introduction consisted of a description of the study and the BEAM+ robot, followed by a short practice driving session with all four input devices. The four driving episodes included driving BEAM+ through a complex track (see Figure 3), featuring two signs with words that the participants needed to read out loud, as well as two hanging objects the participants had to avoid. Two different start/stop-locations and two driving directions resulted in a total of four track variations. Every participant drove through each of the track variations and used each of the input devices.

Data collection. An SRS-questionnaire was used for comparison and triangulation. The SRS questions were aimed directly at assessing the cognitive load experienced by the pilots, in line with $[3,7,14]$, and consisted of four semantic differential scales. The scales, inspired by the NASA-TLX questionnaire [8], consisted of: 1) Reassurance, 2) Effortlessness, 3) Simplicity, and 4) Easiness. The participants answered these questions after each driving episode and were instructed to think aloud about their experience. Other recorded data included: a) background information, b) recording of participants' body movements, computer monitor, and robot's movements in the remote environment, c) a semantic differential scale questionnaire for measuring UX (see [4]), d) deviceranking questionnaire, and e) interviews.

\section{Results and Discussion}

We compared multiple sources of empirical evidence obtained in the study to find out whether the 


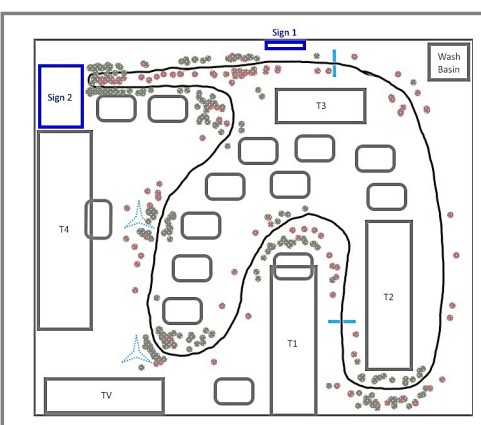

Figure 5: Collisions (green dots) \& missed ST Responses (red dots)

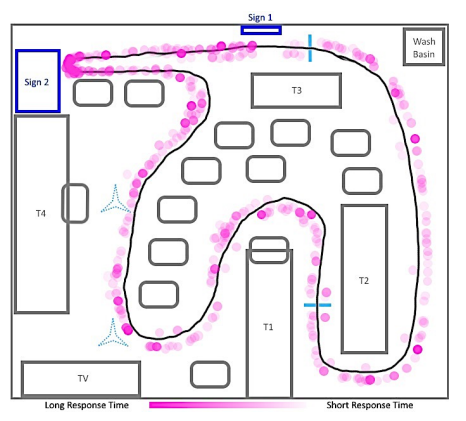

Figure 6: ST Response Time.

Darker color $=$ longer RTs assessment of cognitive load based on performance indicators of the Secondary Task - ST failures (i.e., missed ST stimuli that require responses) and slow response times - was consistent with other, objective and subjective, indicators of cognitive load. We used two analytical strategies. The aim of "track-based analysis" was to establish whether the most challenging parts of the track correlating with a higher number of ST failures and slower responses. The "device-based analysis" intended to establish whether the subjective assessment of a device as more difficult to use was consistent with ST performance indicators.

\section{Track-based analysis}

The number of bumps and crashes on the track correlated with the number of ST-failures (see Figure 5) as well as slow response times (see Figure 6). Sections highlighted by the data as most challenging, also were the same that the participant believed to be hardest, i.e., the part with hanging obstacles, the U-turn, and passing through the narrow part between chairs. The start/stop positions of the track had a high degree of ST-failures, mostly because some participants forgot the Secondary Task in the beginning. It suggests that using a reminder, e.g. a familiar face, as a start signal could improve the method.

Device-based analysis

The ranking of input devices based on ST performance indicators was similar to, but somewhat different, from the ranking based on participants' subjective assessment of the devices. On average the participant ranked Keyboard the best, Game Controller second, and, on a tied third place, Dance Pad and Mouse. The SRS, on all four questions, follow the same pattern. While the Keyboard also scored best on ST-failures and average response time, it was followed by Mouse, Dance Pad, and Game Controller. Familiarity is a probable cause why Mouse scored better, and Game Controller worse, on the ST than on the ratings. Game Controller is second to Keyboard in having most failures-free runs, indicating that an experienced user can utilize the device efficiently. The familiarity of the mouse device resulted in good performance but was seen as an improper device for the activity.

One participant noted that when using Dance Pad, the visual focus was divided between the screen and looking down at the controller. Visual focus failures are predicted to be higher for Dance Pad, than other input devices, due to it being positioned on the floor.

\section{Conclusion and Future Work}

This paper shows that measuring cognitive load through secondary task performance in combination with other methods is a feasible approach that should be considered in controlled experiments. This study presents a Secondary Task method that is simple and easily implementable, designed to be used in combination with other evaluation instruments. The STmethod provided results that complement other instruments and generated further insights into user experience.

Two directions of future work on the method can be identified. The first one is applying the method more widely in further comparative analyses of various MRP system designs. The second one is further development of the instrument in order to address the following issues: errors caused by distributed visual focus, multiple ST-failures during start, and time-consuming data analysis. 


\section{Acknowledgments}

The study was supported by The Swedish Research Council, grant 2015-05316. The study has been partly reported in a master's thesis of the second author [5].

\section{References}

1. Roland Brunken, Jan L. Plass, and Detlev Leutner 2003. Direct Measurement of Cognitive Load in Multimedia Learning. Educational Psychologist 38 1: 53-61.

2. C. Melody Carswell, Duncan Clarke, and W. Brent Seales. 2005. Assessing Mental Workload During Laparoscopic Surgery. Surgical Innovation 12, 1: 80-90.

3. Alex Chaparro, Joanne M. Wood, and Trent Carberry. 2005. Effects of age and auditory and visual dual tasks on closed-road driving performance. Optometry and vision science 82,8 747-754.

4. Karin Danielsson and Patrik Björnfot. 2017. A semantic scale for evaluating the UX of a MRP system. Proceedings of the European Conference on Cognitive Ergonomics 2017, ACM, 59-60.

5. Azadeh Farshidi. 2017. A Secondary Task Test for Evaluating Cognitive Load of MRP Pilots. Master's thesis. Department of Informatics, Umeà University, Sweden.

6. M.A. Goodrich. 2004. Using Models of Cognition in HRI Evaluation and Design. Defense Technical Information Center.

7. Faizal A. Haji, Rabia Khan, Glenn Regehr, James Drake, Sandrine de Ribaupierre, and Adam Dubrowski. 2015. Measuring cognitive load during simulation-based psychomotor skills training: sensitivity of secondary-task performance and subjective ratings. Advances in Health Sciences Education: Theory and Practice 20, 5: 1237-1253.
8. Sandra G. Hart and Lowell E. Staveland. 1988. Development of NASA-TLX (Task Load Index): Results of Empirical and Theoretical Research. Advances in Psychology 52: 139-183.

9. Victor Kaptelinin and Bonnie A. Nardi. 2006. Acting with technology: Activity theory and interaction design. MIT press.

10. Annica Kristoffersson, Silvia Coradeschi, and Amy Loutfi. 2013. A review of mobile robotic telepresence. Advances in Human-Computer Interaction 2013: 3.

11. Min Kyung Lee and Leila Takayama. 2011. Now, I have a body: Uses and social norms for mobile remote presence in the workplace. Proceedings of the SIGCHI Conference on Human Factors in Computing Systems, ACM, 33-42.

12. Paul M. Linton, Brian Plamondon, A O. Dick, Alvah Bittner, and Richard E. Christ. 1989. Operator Workload for Military System Acquisition. .

13. Fred G. W. C. Paas and Jeroen J. G. Van Merriënboer. 1994. Instructional control of cognitive load in the training of complex cognitive tasks. Educational Psychology Review 6, 4: 351371

14. Annie Rydström, Camilla Grane, and Peter Bengtsson. 2009. Driver Behaviour During Haptic and Visual Secondary Tasks. Proceedings of the 1st International Conference on Automotive User Interfaces and Interactive Vehicular Applications, ACM, 121-127.

15. Katherine M. Tsui and Holly A. Yanco. 2013. Design Challenges and Guidelines for Social Interaction Using Mobile Telepresence Robots. Reviews of Human Factors and Ergonomics 9, 1: 227-301.

16. Bin Xie and Gavriel Salvendy. 2000. Prediction of Mental Workload in Single and Multiple Tasks Environments. International Journal of Cognitive Ergonomics 4, 3: 213-242. 